\title{
A Qualitative Exploration Into The Role Of Organisational Or Institutional Reputation And Integrity In The Theory And Practice Of Public Administration In South Africa: A Drive Towards Creating A Credible, Sustainable And Democratic Public Administration Model For Mzansi Africa (South Africa)
}

\author{
Peter Lebosa Bogopane, PhD, Public Administration \\ North West University, Mafikeng Campus, South Africa
}

doi: 10.19044/esj.2016.v12n14p134 URL:http://dx.doi.org/10.19044/esj.2016.v12n14p134

\begin{abstract}
This manuscript deals with and reports on the qualitative exploration of and analysis into the most pertinent, yet severely ignored concept of "institutional/organisational reputation and integrity" in public administration and management. The study was inspired and motivated by the fact that even though theme plays a significant role in influencing trust and support in our public and private entities alike, very little has been written about the concept. The article commences by providing a general theoretical background to and definition of this theme. It also presents a brief overview on the roles of and the importance this largely neglected concept has in enhancing, consolidating, and improving the position of governance and service delivery of both our public and private entities. More significantly, the author identifies four (4) phases/facets/dimensions that are associated with institutional/organisational reputation and integrity, namely: Performative reputation; Moral reputation; Procedural reputation; and Technical reputation, and uses them as the hallmarks for this qualitative exploratory analysis. Methodologically, the study employs a qualitative phenomenological and empirical research paradigm and design, to understand the functionality and performance of institutional/organisational reputation and integrity within the context of South African public and private entities. Qualitative data collection and gathering methods such as (Participant observation; In-depth interviewing; Document study; and Case study) and qualitative data analysis and interpretation techniques such as (Qualitative Content analysis; and qualitative Case analysis) are used to collect and gather data and to analyse and interpret data respectively. The
\end{abstract}


population of the study is described as comprising of all public and private entities serving the people and doing business in South Africa. A judgmental and/or purposive sampling technique is employed as a way of selecting study participants. Findings will be arrived at, and on their basis, recommendations will be clearly provided and articulated.

Keywords: Institutional/Organisational reputation, Integrity, Performative reputation, Moral reputation, Procedural reputation, and Technical reputation

\section{Introduction}

The central point of departure for this manuscript is the assertion that understanding how public institutional and organisational reputations are formulated and incidentally cultivated is essential to comprehend the role of public administration in a democracy. In essence, public administration as a field of theory and practice is a good deal more complex than the simple reputational and signaling games common to formal theories of bureaucracy would suggest. Carpenter and Krause (2012:) submit that:

These theories and models can be highly useful for particular types of puzzles, but they fail to capture some essential elements and reputations and audiences as they are experienced in the realm of public administration. To begin with, the audience are multiple and diverse, so satisfying one audience (e.g. a congressional committee) often means perturbing another (e.g. the media). More powerfully, the complexity of public agencies means that there is not, as in the signaling games of formal theory, a single underlying "type" that characterises the agency's values, preferences, intentions, and resolve.

In a democratic country such as South Africa public administration and management cannot exist and function in isolation, simply because government, government agencies, and government institutions and departments, both make and administer public policies in a richly textured political environment that is composed of audiences, including but not limited to: elected officials, clientele groups, media, policy experts, and ordinary citizens of the country. The rationale behind this article is to provide for a basis upon which the reputation and integrity of our public institutions, departments, agencies, and officials could be founded, enhanced, and consolidated towards improving governance and service delivery to the multitudes of South Africans. To address pertinent issues underlying this study, the article adopted a qualitative paradigm/approach, thus using qualitative data collection and gathering methods (such as participant observation, in-depth interviewing, document study and case study) for collection and gathering of data, as well as qualitative data analysis and interpretation techniques (such as qualitative content analysis and qualitative case study analysis) for analysis and interpretation of data. Non-probability 
purposive judgmental sample is used based on the aim and purpose of the study. The choice and selection of this qualitative paradigm/approach is informed and influenced by the nature of the research problem, research questions, and the research objectives underlying the study.

\section{In-text citations}

- In an author-date style, in-text citations usually require the name of the author(s) and the year of publication.

- A page number is included if you have a direct quote. When you paraphrase a passage, or refer to an idea contained in another work, providing a page number is not required, but is "encouraged", especially when you are referring to a long work and the page numbers might be useful to the reader. Example: (Jones, 2002)

- Background

- The problematic dynamics and issues in the current theory and practice of public administration in South Africa require a critique of how the reputation and the integrity of our public institutions, departments, agencies, and officials could be enhanced and consolidated for effective, efficient, and sustainable public governance and service delivery. Within the context of South Africa, the public institutions'; departments'; agencies'; and officials' credibility does not necessarily translate to anything substantial, as there are still myriad of governance and service delivery challenges that have become overwhelming for the government. In South Africa, for example, the sheer scale of the problem of ageing and decaying infrastructure that supports bulk services, plus the ever-increasing demand for housing and services to mushrooming informal settlements are totally crippling and paralysing. Can this weak position coupled with the realities of high poverty in the rural areas and stubborn unemployment rates in the periurban areas of the country really align with the needs and aspirations of the communities? (Department of Co-operative Government and Traditional Affairs, 2009)

- Many a year times, the public financial administration position of various public institutions, departments, and agencies in government remains untenable as they dismally fail to adhere to or comply with the provisions of both the Constitution of the Republic of South Africa Act, Act 108 of 1996, Public Finance Management Act, Act 1 of 1999, Municipal Finance Management Act, Act 56 of 2003, Prevention and Combating of Corrupt Activities Act, Act 12 of 2004, and National Treasury Regulations. For example, this was clearly highlighted in the Auditor-General Report of 2006/2007. In terms of the said Constitution, a functional and performing government is viewed as one that must structure and manage its administration, budgeting, and planning processes to give priority to the 
basic needs and aspirations of the citizens, to promote social and economic development of the country, and participate actively in national development programmes and projects.

- $\quad$ Evaluation and monitoring of national development programmes and projects is a prerequisite and must never be compromised in any way. In acknowledging the significance of this submission, Kotze (1997) advises that:

- Development, in the sense of positive change (especially in Third World countries), is therefore a process. Such development must ideally occur through democratic and consultative practices, through identifying (as accurately as possible) and acting on what is good for people in a particular context...the development process will lead to the greater material and spiritual welfare of the individual person and of the society concerned, and in turn, to the abolition of poverty. Development efforts will lead to more coherent national economy and a better organised government.

- Based on this assertion, it becomes imperative for public administration officials (especially those who are tasked with the responsibilities of administering and running public institutions, departments, and agencies) to be mindful of their own reputation and integrity and that of the public organisations that they administer and run. They must be beyond reproach, and must be constantly held publicly accountable not only for the decision that they make and the actions that they take, but also for the manner in which they apply and utilise public financial resources (i.e. their reputation and integrity).

- Theoretical Perspective

- This manuscript explores the significance of public institutional reputation and integrity in the theory and practice of public administration in South Africa. Within the context of this study, institutional reputation and integrity is understood to represent and reflect a set of beliefs regarding an institution's capacities, intentions, history, mission and vision that are incorporated in a network of multiple stakeholders and audiences. This work is based on the assertion that:

- The way in which organisational reputations are formed and subsequently cultivated is fundamental to understanding the role of public administration in a democracy. Accordingly, a review of the basic assumptions and empirical work on organisational reputation in the public sector identifies a series of stylised facts that extend our understanding of the functioning of public agencies.

- $\quad$ In essence, Carpenter and Krause examine the relationship between organisational reputation and bureaucratic autonomy. In modern democracies, public administration cannot operate in an institutional vacuum, precisely because government institutions, departments, agencies, 
and officials both make and administer public policies in a richly textured political environment that is composed of diverse audiences, including, but not limited to: elected officials; clientele groups; the media; policy experts; and ordinary citizens as members of the public. (Carpenter and Krause, 2012)

- In assessing this complex situation facing our public institutions, departments, public agencies, and public officials alike, one would assume that at least three vital challenges become eminent in this particular case, namely, (1) how will under these circumstances would democratic government broad-based support for its institutions, departments, agencies, and public officials and their activities? (2) How will such government stir a vessel amid hazardous shoals (enemies and dissatisfied supporters?) and (3) how will such a government continue to maintain and project judicious combination of consistency and flexibility? Public administrators' ability and capacity for handling these administrative challenges rest heavily on organisational/institutional reputation and integrity. (Carpenter\& Krause, 2012)

- Definition of the key concept

- The key concept pertinent to this study is "organisational/institutional reputation" and it is defined by Carpenter (2010a) as:

- A set of beliefs about an organisation's capacities, intentions, history, and mission that are embedded in a network of multiple audiences

- Hence, public administrators at all levels of the public organisations, institutions, departments, and agencies, should spend most of their available time striving to cultivate a reputation that will enable them not only to accrue and solidify autonomy (Carpenter 2001; Rourke 1984; Wilson 1989), but also to offer a protective shield in the presence of opposition in the form of hostile external audiences (Hood 2011)

- Generally, the behaviours of the audience's members that the public institutions, departments, agencies, and officers serve and interact with, are usually shaped by their beliefs and perceptions on what tasks these public entities and officials can and cannot perform effectively and efficiently. Central to this is also the actions taken and decisions made by these public entities and officials. What is also critical, as mentioned earlier, is that institutional/organisational reputations are featured in the beliefs held by external audience members such as elected public officials, clientele groups, the media, and ordinary citizens. These reputations are also developed internally by the internal character of the public administrative organisations/institutions and public officials. In this regard, Romzek (1990) submits that:

- The literature on public service motivation offers compelling empirical evidence that agency personnel are more likely to be motivated to 
the greater good of the agency (and public service in general)when they exhibit strong organisational commitment and identity.

- Moreover, Wright (2007) and Wright and Pandey (2008) agree that:

- When the intrinsic value of the agency's mission is deemed worthwhile, when they can operate in an administrative environment that encourages strong professional norms, and when there are clear hierarchical lines of authority and internal procedures that empower personnel the chances for strong organisational/institutional reputation and integrity would be secured, enhanced and consolidated

- Subsequently, one of the intentions of this study is to focus on both the external and internal features of institutional/organisational reputations as applied to the study of public administration (Moyniham and Pandey2007). In taking this process forward, this article will firstly look into the theory of administrative foundations on institutional/organisational reputations; secondly, look into the institutional/organisational reputations of public entities; thirdly, look into the implications of institutional/organisational reputations; and fourth and lastly, look into the impediments to sound institutional/organisational reputations and integrity within the context of South Africa.

- The nature and foundations of institutional/organisational reputations

- The theoretical origin and history of institutional/organisational reputation-based study in public administration can be traced in the traditional writings of the field of public administration. These writings embed insights on this important theme. According to Carpenter and Krause (2012):

- These include the classic texts of Simon, Smithburg, and Thompson ([1950] 1991, 189,348) and Herbert Kaufman (1981, 10, 26, 76, 131, 145, 164,173). In his widely cited treatise Bureaucracy: What Government Agencies Do and How They Do It, James Q. Wilson discusses reputations repeatedly without focusing on them or theorising about them (1989, 46, 74,77, 80-81, 97, 120,182,190,191,197,199,205,209,222,252,317). Hence as a set of focused academic writings, the reputation-centered account of administration and administrative politics is in relative infancy. Reputation and administration make up an emerging synthesis, we will argue, because we are approaching the point at which there is enough work related to these concepts,

-

(5)

- themes, and theories to glean some general principles and "stylised facts”. In turn, this can offer sound guidance for future research seeking to understand how organisational reputations affect the conduct of public administration in highlighting the nature and scope of institutional/organisational reputation as a multifaceted concept that 
comprises a set of beliefs, about an institution's/organisation's capacities, intentions, history, and mission that is embedded in a network of multiple audiences, Carpenter (2010b) mentions about four crucial dimensions of an institution's/organisation's reputation that will shape its audience's reactions and the associated behaviours of its members and officials, namely:

- 1 . Performative reputation. This facet looks at the question of whether the public institution/department/agency/official can do the job. Can the said entities execute charges on their responsibility in the manner that is interpreted as competent and perhaps efficient?

- 2. Moral reputation. In this dimension the ethical $/ \mathrm{moral}$ question is raised and addressed. In this instance, notice is taken of whether the public institution, department, agency or public official is compassionate, flexible, and/or honest. Do these entities, for example, protect the interests of their clients, constituencies, and or members?

- 3. Procedural reputation. Under this facet, the fundamental question is: C`D Does the public institution, department, agency, and/or public official follow normally accepted rules and norms, however good or bad its decisions? and finally

4. Technical reputation. Here, the focus is on the question whether the public institution, department, agency, and/or public institution, department, agency, and/ or public official have the capacity and skill required for dealing in complex environments, independent of and separate from its actual performance?

- The implications of institutional/organisational reputations

- The essential focus of a reputation-based account of a public institution/department/agency and /or public official is that of the audience that these public entities are established to serve. A crucial point of this perspective is that public entities should by faith and trust as well as training, be sincerely aware of their audiences, and the fact that their audiences will always monitor them. Note must also be taken of the fact that not all audiences have the same influence, but at least some of them are being watched explicitly and/or implicitly by public administrators for purposes of accurately gauging expectations regarding external demands placed on them. Within this context, Gioia, Schultz, and Corley (2000) submit that:

- What audiences see is not the perfectly tuned or visible reality of the agency, but an image of that embeds considerable uncertainty and ambiguity. Complex public organisations are seen "through a glass but dimly" by their manifold audiences. To begin with, the audiences are diverse, so satisfying one audience (e.g. a congressional committee) often means perturbing another (e.g. the media). More powerfully, the complexity of public agencies means that there is not, as in the signaling games of formal theory, a single 
underlying "type" that characterises the agency's values, preferences, intentions, and resolve.

- $\quad$ Possible impediments to institutional/organisational reputation

- It is particularly important to understand that the reputation of the public institutions/organisations and public officials is central to and bounded up with the legitimacy of state/government. Notwithstanding, both the external and internal audiences (groups)can serve as "warning bells" to alert politicians, public officials and other overseers of actions and decisions that concern and/or bother them. In discussing the apparent possible impediments to institutional/organisational reputation, there should be a need for both scholars and practitioners to explore and examine the image considerations that impede and buffet any public institution/organisation/agency and their administrators. In addressing this challenge, Carpenter and Krause (2012) identified basic facts about public agencies that are known to be true, yet existing theories are poorly equipped to handle, namely that:

- $\quad$ Public agencies are differentiated, more so than other recipients of delegated political authority and power. Accordingly, there are dozens or hundreds of members in any legislature, but they often share common institutional characteristics: chosen according to the same laws of election, endowed with similar though not identical power. They meet together in the same physical spaces, are lobbied by the same set of actors, and vote on identical propositions. This differentiation means that agencies are harder to characterise, which means (counterintuitively, but powerfully) that agency reputation is all the more important because organisational images offer forceful simplifications of more complicated agency realities, and they are often relied on more heavily when the agency is more complicated;

- Not everyone in a public agency is on the same page. In both public administration and business administration, it is a common feature that the information, assumptions, resources, and intentions of some agents are partially or wholly concealed from others. This concealment can be intentional or unintentional, yet the result is the same: the left hand rarely knows well what the right hand is doing. This fact replicates, in part, the centrifugal forces of administration. In Frederickson's (1999) term "the disarticulated state" complex public organisations and networks must decentralise authority and operations, and whether it is geographic or specialisation based on a span of control, decentralisation multiplies the opportunities for differential action. Yet the differentiation is also professional and political. Professionally, some officials in public organisations speak one language, while others speak a different tongue. Politically, coalitions emerge within and across organisations. They emerge 
in support of and opposition to certain rules, policies, and personalities, and this everyday "office politics” can further multiply differentiation;

- External audience members view public agencies as being more unified than they actually are. Organisational reputations attach themselves to entities whose members and parts are so disparate that it is impossible for all or even most of them to be culpable or praiseworthy for the actions that give rise to the image in the first place (Carpenter 2010b). Even though it is fashionable to treat public administration and management as a networked process rather than a bureaucratised process (Frederick 1999; O’Toole 1997), the cultural, political, and social reality of organisational image remains. Even if the actual network of agents delivering public services is manifold and complex, observers and audiences nonetheless will make inferences and judgments-judgments that are culturally, economically, politically, and socially consequential-about what they and others perceive as unified entities responsible for outcomes;

- Public agencies often treat as irreversible those decisions that can be reversed, legally or technologically. These include product approval decisions (Carpenter, 2002, 2004), public announcements and warnings, (Maor 2011), the issuance of new rules and scientific determinations, and behaviour around agency jurisdictions (Maor 2010). Reputation dynamics do not always induce agencies to cling to the past choices or rulings - there may be strong audience incentives for revising decisions. Yet the projection of consistency should not be underestimated as a force shaping agency choice;

- Public agencies engage in "contingent actions” as a means of hedging against policy or technical uncertainty. That is, organisations actively will attempt to keep their options open in order to remain flexible and thus avoid falling prey to pathologies of path-dependent decision-making. For example, Carpenter(2010b) and Carpenter and Moore(2007) demonstrate that public agencies may avoid making concrete predictions or commitments in some cases, trying to avoid commitment to a hypothesis that can be publicly falsified or to preserve space for future action;

- Agencies may emulate the actions and structures of others as a way of insulating themselves from criticism by audience members. In organisational sociology, this legitimation perspective powerfully explains the persistence and uniformity of many structural arrangements (Meyer and Rowan 1977). Yet reputation-based emulation also has been observed in both US economic and fiscal forecasting behaviour (Krause and Douglas 2005, 2006; cf. Krause and Corder 2007), as well as in the realm of administration of US federal public lands (Kunioka and Rothenberg 1993), as a means of blame avoidance. The rationale for such behaviour among agencies engaged in the same set of functional tasks is the desire for organisational maintenance (see also Wilson 1989; cf. Downs 1967); and Agencies have 
multiple audiences; therefore, satisfying some audience subset often means upsetting others or projecting ambiguity. The public administrator who serves multiple publics often must chart a course of action that is responsive to several of them at once; this may mean-appropriately for responsive, democratic, and accountable management-speaking or presenting intensions in ways that refrain from (1) committing to a specific interpretation, (2) favouring one audience over another, (3) privileging or insulting one audience relative to another, or (4) committing forcefully to a future course of action. This acknowledgement and theorisation of multiple audiences is one of the central factors differentiating reputation-based theories from public administration and from closely related, but different, "blame game" and "blame avoidance" theories (e.g. Hood 2011). While blame avoidance has become an important tool for theory and empirical explanation and for public administration policy initiative and reform, theoretical and empirical studies in the "blame avoidance" literature remain, at present, insufficiently attentive to the multiple audiences, multiple constituencies, and multiple publics of agencies. In fact, what may look like blame avoidance in some public administration contexts (Hood 2011, chap. 7), may represents a strategy of negotiating among multiple audiences.

- On the basis of the above empirical overview, this manuscript sought to explore and analyse the position of the role of institutional/organisational reputation in modern democratic South Africa as a developing country. In undertaking this research discourse, the article starts from the premise that the country does have the state of the art public and private infrastructure that is second to none. However, the existence of such an infrastructure does not necessarily and automatically translate to effective, efficient, viable, sustainable, and legit governance and service delivery. This study identifies and highlights five fundamental challenges that seem to pose a serious threat to the institutional/organisational reputation and integrity of our public and private entities, namely: (1) poverty/deprivation; (2) inequalities; (3) unemployment; (4) racism; and (5) blatant corruption

- Poverty and/or deprivation. The nature and level of poverty and deprivation in the country are extremely alarming and disturbing. The stubbornness of these two similar, yet identical challenges is prevalent in both rural and urban areas of the country. Davids et al (2009) explain that:

- The word "poverty" conjures images of starving children, overcrowded informal settlements and ragged street children. These images form the basis of many peoples' understanding of poverty. Poor people, however, have their own understanding and interpretation of their social reality, and this is often removed from the outsider's perspective and the jargon sometimes used by academics, politicians, and consultants whose 
knowledge of poverty often comes from books, television documentaries, newspapers, and questionnaire interviews with the poor.

- $\quad$ Deprivation in this context refers to the complete and total exclusion of certain segments of the country's population from participation in the mainstream social, economic, and political activities mainly on the basis of their race, colour, gender, religious beliefs etc.

- Inequalities. The concepts of "poverty" and "inequality" are somehow intertwined. As Bhorat et al (2003) put it:

- A society with a low level of poverty may still be a society with a high level of inequality. The United States clearly has a lower level of poverty than Tanzania, but it also has inequality. A fairly equal society may still have a high level of poverty. Many developing countries would have a lower Gini coefficient than South Africa, thus a lower level of inequality, but poverty is much worse. Inequality with less poverty is more attractive than inequality in poverty. A society in economic take-off is will, whilst in the transition from poor to less poor, experience rising inequality. This is as inevitable as the night following the day. Whilst progress is being made with poverty reduction, inequality may be worsening. The goal of transforming the ownership and composition of the economy to reflect the country's demographics more accurately will inevitably entail a worsening of the Gini Coefficient within the Black community itself. (South African situation)

- In South Africa, it appears that poverty and inequality respond differently to the phenomena of growth and development. In reality, as the level of growth and development increases, it certainly rolls back poverty on the one hand, but it also exacerbates the problem of inequality on the other. This, in turn, places policy makers in an awkward position in that it forces them make difficult choices such as: which one of the two gets the highest priority? In socialist countries priority was placed mainly on equality that eventually ended with everybody being equally poor and societies at the state of collapse. Examples include, but are not limited to Julius Nyerere's African Socialism, the Soviet Union and the countries in Eastern Europe. However, under rampant growth philosophies, combating poverty is the priority, best examples being that of present-day China, Korea, Taiwan, and Malaysia. (Bhorat et al, 2003).South Africa is one of the countries that have the highest level of inequality across the globe, thus raising concerns about the reputation and integrity of her public institutional/organisational entities.

- Unemployment. Unemployment is one of the pressing societal challenges in South Africa, which needs innovative, viable, bold, and meaningful policy strategies to address and tackle. Moreover, tangible actions and commitment instead of rhetoric empty noises are required to minimise the negative impacts of this horrendous and undesirable socio- 
economic and political problem. Fourie (2004)asserts that this can be achieved through:

- An array of variables such as: the correct definition of the problem; the accurate identification of causal links; and the just determination of realistic objectives, all of these having an impact on whether or not deviations might occur during the implementation stage

- Racism. Racism still remains a threat to and poses a serious challenge to the newly found South African democracy. Racism is truly a scourge that humiliates both the perpetrator and the victim, and as such we need to guard against it lest we lose our dignity, reputation and integrity as a nation. The most unsettling, and therefore disturbing truth, is that the danger is that a racist mindset is having the propensity of having passed down from generation to generation, particularly here in South Africa, in spite of the fact that there is this premise that any human being deserves dignity and integrity regardless of his/her racial background or socio-economic standing. Sinothile and Shilaho (2016) advise that: To address this problem head-on, will require concrete measures at the legislative level that are geared towards preventing, reducing, and even eliminating racism in all its manifestations. More specifically, it should be imperative to constantly and consistently create a society that has no room whatsoever for racial discrimination or any other discrimination for that matter. . On the other hand, all South Africans must owe it to themselves to oppose racism through social integration and nationhood. What we cannot overemphasise is the fact that we cannot undo the legacy of a unique system such as apartheid overnight. It is our responsibility to continuously strive towards reconciliation, transformation and nationhood as South Africans. After all, nation states are political constructs and therefore have to be consistently moulded through social engineering. It is dangerous to democracy for everyone in this society to hold the view that racism is a given. Since time immemorial all justifications advanced by apologists of this prejudice have been proven untrue. That notwithstanding, some people in our society are still prone to racism and this psychic problem is what we have to address.

Blatant corruption. Corruption is effectively embedded and entrenched across the globe, including South Africa. In this manuscript, the concept of 'corruption' is used to represent the view that corruption intricately linked with the shaping of decisions against the public interest made by bureaugarchs who include politicians and business people, hence public anger about government corruption, perceived or real, has become associated with attendant violent protests (Provost and Chalabi, 2013).Nevertheless, societal understanding of rules and interpretations of deviations therefrom, corruption and attendant public perceptions are functions of "personal values and moral views" (Melgar, Rossi, and 
Smith,2010)Notwithstanding, and whatever the meaning of corruption is, the pertinent position should be that a high standard of professional and ethical conduct in the public and private sector remain to be a critical issue, and these entities must increasingly be concerned about the nature and extent of corruption in their respective countries (Republic of South Africa). What is more worrying is that, in South Africa and many other developing democracies, scandals involving public officials, regarding unethical and corrupt conduct, have captured world attention (United Nations), and this in itself has provoked widespread condemnation and global discourse on good governance that is underpinned by a call for governments to be more proactive in the fight against corruption (Mollo, 2010).

These and other similar barriers impose serious impediments on public and private agencies in South Africa alike, and thus threatening the viability and sustainability of their reputation and integrity

Recommendation 2: Regarding Finding 2 above, recommendation is made to the effect that leadership in this entities must start to adopt a new positive attitude towards institutional/organisational reputation and integrity and strive to define and determine not only a fresh view of these important organisational concepts, but also earnestly create and adopt a clear vision, mission, and commitment towards institutional/organisational reputation and integrity for the sake of the viability, sustainability, and success of their entities and their audiences

Recommendation 3: In the case of Finding 3 above, this manuscript recommends that a clear and conscious decision must be made and serious action be taken by leadership in these entities to ensure that well-taught off, well-engineered, and well-oiled structures, systems, policies, processes, programmes/projects aimed at fast-tracking and strengthening institutional/organisational reputation and integrity are sought and put in place as a matter of urgency and without any further delay. This will subsequently enables the leadership to integrate and link its visionary and foresighted skills and strategies to their institutional/organisational reputation and integrity, that will eventually lead to the improvement of the functionality and performance of their respective entities in the areas of governance and service delivery, leading to the restoration of the lost trust and confidence from the public that they serve in case of the public sector, and the clients and customers and clients that they have, in case of the private sector.

\section{Conclusion}

This manuscript dealt with the qualitative exploration of and analysis into the most pertinent, yet severely ignored concept of "institutional/organisational reputation and integrity" in public 
administration and management. The study started by providing general and theoretical background to and definition of the concept. It also presented a brief overview on the roles of and the importance of this neglected concept have in enhancing, consolidating, and improving governance and service delivery of both our public and private entities. More importantly, the author identified four (4) phases/facets/dimensions that are associated with institutional/organisational reputation and integrity, namely: Performative reputation; Moral reputation; Procedural reputation; and Technical reputation, and used them as the hallmarks for this qualitative exploratory analysis. Methodologically, the study employed a qualitative phenomenological and empirical research paradigm and design, to understand the functionality and performance of institutional/organisational reputation and integrity within the context of South African public and private entities. Qualitative data collection and gathering methods such as (Participant observation; In-depth interviewing; Document study; and Case study) and qualitative data analysis and interpretation techniques such as (qualitative Content analysis and qualitative Case study analysis) were used to collect and gather data and to analyse and interpret data respectively. The population of the study was described as comprising of all public and private entities serving the people and doing business in South Africa, and a judgmental and/or purposive sampling technique was employed as a way for selecting study participants. Findings were arrived at, and on their basis, recommendations provided and clearly articulated

\section{References:}

Babbie, E. and Mouton, J. 2001.The Practice of Social Science Research. Cape Town: Oxford University Press

Bhorat, H. van der Berg, S. and van der Aardt, C. 2003. Breaking the grip of Poverty and Inequality in South Africa 2004-2014: Current trends, issues, and future

policy options.http://www.econrsa.org/system/files/workshops/papers/2013/mushon gere.pfd.Accessed 20 March 2013

Carpenter, D.P.2001.The Forging of Bureaucratic Autonomy: Reputations, Networks, and Policy Innovation in Executive Agencies, 1862-1929. Princeton, NJ: Princeton University Press

Carpenter, D.P. 2002.Groups, the Media Agency Waiting Costs, and FDA Drug Approval American Journal of Political Science 46(2): 490-505.

Carpenter, D.P. 2004.Protection without Capture: Product Approval by a Politically Responsive, Learning Regulator. American Political Science Review 98(4): 613-31 
Carpenter, D.P. 2010a Institutional Strangulation: Bureaucratic Politics and Financial Reform in the Obama Administration. Perspectives on Politics 8(3): 825-46

Carpenter, D.P. 2010b Reputation and Power: Organisational Image and Pharmaceutical Regulation in the FDA. Princeton, NJ: Princeton University Press.

Carpenter, D.P. and Moore, C.D. 2007.Robust Action and the Strategic Use of Ambiguity in a Bureaucratic Cohort: FDA Scientists and the Investigational New Drug Regulations of 1963 in Formative Acts. American Politics in the Making, edited by Stephen Skowronnek and Matthew Glassman, 340-62 Philadelphia: University of Pennsylvania Press

Carpenter, D.P. and Krause, G.A. 2012.Reputation and Public Administration Public Administration Review 72(1): 26-32 January/February 2012

Davids, I. Theron, F. and Maphunye, K.J. 2009.Participatory Development in South Africa: A development Management Perspective 2nd ed. Pretoria: Van Schaik

De Vos, A.S. Strydom, H. Fouche, C.B. and Delport, C.S.L. 2011.Research at Grass Roots: For the Social Sciences and Human Service Professions. Pretoria: Van Schaik

Downs, A. 1967.Inside Bureaucracy Boston: Little, Brown

Fourie, P. 2004. Public Policy: theoretical exploration and synthesis. Politeia 23(1): 4-32

Frederickson, H.G. 1999. The Repositioning of American Public Administration (John Gaus Lecture) PS: Political Science and Politics 32(4): 701-11

Gioia, D.A. Schultz, M. and Corley, K.G. 2000 Organisational Identity, Image, and Adaptive Instability Academy of Management Review 25(1): 6381 (15)

Hood, C. 2011. The Blame Game: Spin, Bureaucracy, and Self-Preservation in Government. Princeton, NJ: Princeton University Press

Kotze, D.A. 1997. Development Administration and Management-A Holistic Approach Pretoria: Van Schaik

Krause, G.A. and Douglas, J.W. 2005 Institutional Design versus Reputational Explanations for Agency Performance: Evidence from U.S. Government Macroeconomic and Fiscal Projections. Journal of Public Administration Research and Theory 15(2): 281-306

Krause, G.A. and Douglas, J.W. 2006.Does Agency Competition Improve the Quality of Policy Analysis? Evidence from OMB and CBO Fiscal Projections Journal of Policy Analysis and Management 25(1): 53-74 
Krause4, G.A. and Corder, J.K. 2007.Explaining Bureaucratic Optimism: Theory and Evidence for U.S. Executive Agency Macroeconomic Forecasts. American Political Science Review 101(1): 129-42

Kunioka, T, and Rothenberg, L.S. 1993. The Politics of Bureaucratic Competition: The Case of Natural Resource Policy. Journal of Policy Analysis and Management 12(4): 700-725

Maor, M. 2010.Organisational Reputation and Jurisdictional Claims: The Case of the U.S. Food and Drug Administration. Governance 23(1): 133-59 Maor, M. 2011. Organisational Reputation and the Observability of Public Warnings in 10 Pharmaceutical Markets Governance (24(3): 557-82

Melgar, N. Rossi, M. and Smith, T.W.2010.The Perception of Corruption International Journal of Public Opinion Research 22(1):120-131

Meyer, J.W. and Rowan, B. Institutionalised Organisations: Formal Structure as Myth and Ceremony. American Journal of Sociology 83(2): 340-63

Mollo, S. 2010. Reflections on Ethical Dilemmas: A South African Perspective. Ottawa: Commonwealth Association for Public Administration and Management

Moyniham, D.P. and Pandey, S.K. 2007.The Role of Organisations in Fostering Public Service Motivation. Public Administration Review 67(1): 40-53

Msomi, S. and Shilaho, W. 2016.Racism Still a Threat to South Africa's Democracy. Center for the Study of Violence and Reconciliation http://www.csvr.org.za|index.php|media-articles|latest-csvr-in-themedia|2262=racism-still-a-threat...

O’Toole, L.J. 1997. Treating Networks Seriously: Practical and ResearchBased Agendas in Public Administration Public Admin9istration Review 57(1):45-52

Patton, M.Q. 2002.Qualitative Research and Evaluation Methods.3rded.Thousand Oaks, CA: Sage

Provost, C. and Chalabi, M. 20132013 Global Barometer The Guardian, 09 July 2013

Republic of South Africa.1996.Constitution of the Republic of South Africa Act, Act 108of 1996 Pretoria: Government Print

Republic of South Africa. 2009. Department of Co-operative Governance and Traditional Affairs Strategic Plan 2009-2014. Pretoria: Government Print

Republic of South Africa. 2003. Municipal Finance Management Act, Act 56 of 2003. Pretoria: Government Print

Republic of South Africa. 2005. National Treasury Regulations for Public Comment in Government Gazette No. 25613 Dated 28 June 2004. Pretoria: Government Print 
Republic of South Africa. 2004. Prevention and Combating of Corrupt Activities Act, Act 12 of 2004. Pretoria: Government Print

Republic of South Africa. 1999. Public Finance Management Act, Act 1 of 1999. Pretoria: Government Print

Republic of South Africa. 2011. Report of the Auditor General to Parliament on a Performance Audit. Auditor-General of South Africa has a Constitutional Mandate as a Supreme Audit Institution. Pretoria: Government Print

Romzek, B.S. 1990. Employee Investment and Commitment: The Ties that Bind. Public Administration Review 50(3): 374-82

Rourke, F.E. 1984. Bureaucracy, Politics, and Public Policy.3rd ed. Boston: Little Brown

Wilson, J.Q. 1989. Bureaucracy: What Agencies Do and Why They Do It. New York: Basic Books

Wright, B.E. 2007.Public Service and Motivation: Does Mission Matter? Public Administration Review 67(1): 56-64

Wright, B.E. and Pandey, S.K. 2008.Public Service Motivation and the Assumption of Person-Organisation Fit: Testing the Mediating Effects of Value Congruence. Administration and Society 40(5): 502-21 